\title{
ENSINAR CIRURGIA: COMO E PARA QUEM?
}

\section{TEACH SURGERY: HOW AND FOR WHOM?}

\section{TCBC-RJ Lisieux Eyer de Jesus ${ }^{1}$}

\author{
Você pode sonhar - e não fazer dos sonhos seus mestres \\ Você pode pensar - e não fazer do pensamento seu objetivo \\ Você pode encontrar o triunfo e o desastre \\ Para descobrir que estes dois impostores são a mesma coisa \\ (Rudyard Kipling, in If)
}

\begin{abstract}
RESUMO: O autor discute a crise atual de formação de médicos e de cirurgiões fazendo uma revisão de dados de literatura atual, referentes ao quantitativo de médicos e discussão de referências éticas e filosóficas da profissão. Há uma diminuição crescente na formação de médicos e cirurgiões, com uma crescente participação de mulheres. Os médicos jovens buscam qualidade de vida e autonomia profissional como principais requisitos profissionais. As síndromes de burn-out são comuns entre os médicos em atividade, e a perda de autonomia profissional tem papel preponderante na determinação da doença. A crise que atinge a profissão médica e as especialidades cirúrgicas tem bases éticas, sociais e financeiras. É necessário e fundamental discutir novos paradigmas de educação e atuação profissional na sociedade moderna (Rev. Col. Bras. Cir. 2008; 35(2): 136-140).
\end{abstract}

Descritores: Educação médica; Cirurgia/educação; Escolas médicas; Estudantes de medicina.

Há, sem dúvida, e a nível mundial, uma crise na formação e quantitativo de mão de obra médica, atingindo preferencialmente os cirurgiões. Em todos os países desenvolvidos faltam cirurgiões neste momento, a formação de médicos apresenta déficits de contingente sistemáticos e a idade de aposentadoria voluntária para médicos diminui sensivelmente.

Na França o número de pediatras diminuiu de 3600 em 1995 para 2570 em 2007, e apenas $20 \%$ das crianças são atendidas por pediatras especializados, numa taxa de 1 pediatra:5300 crianças. ${ }^{1}$ No Brasil em torno de 1/3 das vagas de residência médica em pediatria e grande parte daquelas destinadas à cirurgia pediátrica também têm ficado ociosas nos últimos anos, baseadas em argumentos tais como a formação sacrificada, a qualidade de vida difícil do profissional maduro e a baixa remuneração proporcionalmente a outras especialidades.

A quantidade de graduados em medicina na Alemanha tem diminuído sistematicamente: entre 1995 e 2005 o número de estudantes de medicina caiu de aproximadamente 85000 para 78000 , e cerca de $1 / 4$ dos formandos se dedicam a atividades não assistenciais. $\mathrm{O}$ número de médicos em atividade clínica abaixo dos 35 anos caiu de $27 \%$ para $16 \%$ nos últimos 15 anos, e a média etária dos médicos se elevou de 46 para 51 anos. Com relação à cirurgia, o problema é ainda maior, considerando que a idade média para a aposentadoria dos cirurgiões na Alemanha é de $56 \operatorname{anos}^{2}$ (para os cirurgiões norte-americanos 57 anos) ${ }^{3}$. Nos Estados Unidos $10 \%$ das vagas em residência de cirurgia geral persistem ociosas a cada ano ${ }^{4}$, a escolha de uma residência em cirurgia geral diminuiu de $12,5 \%$ dos estudantes há 20 anos para $6 \%$ em 2003, e 3/4 dos egressos das residências de cirurgia geral se encaminham para alguma especialidade ${ }^{5}$. Em 2004 formaram-se apenas cerca de 250 cirurgiões gerais em todo o território americano, e o país importa sistematicamente mão de obra estrangeira, em especial de países em desenvolvimento. ${ }^{2,5}$

No Brasil 5,5\% dos médicos são cirurgiões gerais, $73 \%$ deles com 3 empregos ou mais ( $24 \%$ com $>=4$ empregos), apesar de uma renda média mensal declarada de 1300 dólares americanos (aqui o fosso entre profissionais de países de primeiro mundo e o cirurgião brasileiro se aprofunda: a média anual de salário de um cirurgião americano médio é de 280000 dólares). 50\% dos médicos brasileiros exercem algum plantão, geralmente presencial, e $38 \%$ destes são profissionais têm mais de 40 anos de idade. ${ }^{6}$

A relação candidato-vaga para residência médica na Universidade Federal do Rio de Janeiro em 2007 apresenta é de 28,67 candidatos/vaga em cirurgia geral $(32,5 \mathrm{em}$ dermatologia), porém uma conclusão apressada no sentido de que a procura de formação em cirurgia é mais do que satisfatória é contradita imediatamente, já que a relação candidato-vaga para cirurgia geral "avançada" é de apenas 4, sinalizando que a persistência de graduandos na especialidade é pequena, em especial se confrontados com relações can-

1. Cirurgiã do Serviço de Cirurgia Pediátrica do Hospital Universitário Antônio Pedro e do Serviço de Cirurgia Pediátrica do Hospital dos Servidores do Estado, Rio de Janeiro- RJ.

Recebido em 10/12/2007

Aceito para publicação em 25/01/2008

Conflito de interesses: nenhum

Fonte de financiamento: nenhuma 
didato-vaga de 29, 12 e 12, respectivamente para cirurgia plástica, cirurgia vascular e urologia. ${ }^{7}$ Estes dados são corroborados por outras instituições. Na Universidade Federal do Paraná, por exemplo, a relação candidato-vaga para residência médica em cirurgia geral no ano de 2007 foi de 15,83 (37 para dermatologia e 28,5 para otorrinolaringologia), contra apenas 2 para o ano de R3 em cirurgia geral e 11,5 para urologia. ${ }^{8} \mathrm{Num}$ problema específico do Brasil, com o reconhecido excesso de escolas médicas, muitas das quais incapazes de formar profissionais adequadamente qualificados, as altas relações candidato-vaga nas áreas básicas assinalam um enorme contingente de jovens médicos privados da oportunidade de formação complementar adequada através da residência médica: > 40\% dos médicos formados não têm oportunidade de cursar um programa de residência. ${ }^{9}$

O problema está claro, mas as explicações são variadas e discutíveis.

Uma das questões mais sérias é a busca de melhor qualidade de vida como prioridade pelos adultos jovens. Há uma mudança conceitual recente do ponto de vista filosófico e existencial neste sentido, com expressão particularizada na profissão de médico, em especial cirurgiões. O estereótipo clássico do cirurgião e sua família próxima mostrava um comportamento "sacerdotal" em que a dedicação profissional irrestrita, compensada por um respeito absoluto a uma figura divinizada, implicava uma vida social restrita e convívio familiar limitado. Jovens modernos não desejam isto para si.

Hoje, seja por aspirações sociais/existenciais ou pela perda de um status antes inquestionável, alguns sacrifícios pessoais necessários durante a formação e atividade profissional são inaceitáveis para os jovens médicos. É necessário recriar o perfil profissional do cirurgião, a fim de atraí-los para a especialidade. O cirurgião clássico resolutivo, corajoso, líder por excelência, heróico (prático, pouco intelectualizado, agressivo, despótico, irresponsável e arrogante, dependendo das circunstâncias, do padrão de julgamento ou do juiz) foi substituído por um profissional de convívio multidisciplinar controlado por resultados e altamente especializado (com pouca autonomia e autoridade, subordinado a gestores, limitado em suas atividades cirúrgicas e permanentemente avaliado, considerando as desvantagens). Aquele "que invade sob controle" substituiu aquele "que cura apesar de todos os riscos". O senso crítico hiperativo e obsessivo habitual nos cirurgiões encontra dificuldades enormes de conviver com este novo paradigma de comportamento e atuação. $\mathrm{O}$ equilíbrio entre intenção, grau de certeza, sucesso e risco tem sido francamente insuficiente para balizar a atuação assistencial. Sem dúvida nenhuma, a combinação entre altos níveis de stress e baixos níveis de poder e resolutividade é a mais tóxica possível. Cirurgiões têm inquestionavelmente altos níveis de responsabilidade, mas sua autoridade tem sido bastante limitada por regras, regulamentos, auditorias, atitudes de outros profissionais, formulários e que tais. Provavelmente a burocratização da atividade médica é uma das grandes responsáveis pelo enfraquecimento do vínculo simbiótico entre "o" médico e "o" paciente, porque necessariamente despersonaliza a relação e insere intermediários na determinação do ato médico (prestação de serviço...).
O treinamento clássico do médico é voltado para o atendimento pessoal a indivíduos e famílias (não para o atendimento grupal ou institucional), para fazer o melhor possível para cada paciente (não para distribuir atendimento dentro de limitações determinadas administrativamente), para assumir responsabilidades de forma pessoal (não para delegá-las), para conhecer e determinar o que é melhor para o paciente (não para debater alternativas). Provavelmente será necessário modificar o modelo hipocrático clássico de formação à luz da nova medicina. Como inserir os seis princípios hipocráticos principais (reverência aos mestres, consideração com os colegas, o princípio "primo non nocere", respeito absoluto à vida, restrição da ação ao seu conhecimento, respeito à privacidade e não abuso de dados de seu conhecimento através da atividade profissional) com as características modernas do exercício da profissão?

Evidência substitui experiência (reverenciar mestres?). Relações entre colegas são limitadas pelos conflitos profissionais, níveis de autoridade e competitividade de mercado. Não lesar tornou-se relativo, considerando os limites éticos dos mecanismos de cura disponíveis contra a necessidade de paliação ou renúncia terapêutica. $\mathrm{O}$ conceito de respeito absoluto à vida tem sido desafiado nas discussões envolvendo eutanásia, abortamento e cuidados terminais. O segredo médico, proteção absoluta ao paciente e renúncia a privilégios a partir das atividades profissionais são questionados, por exemplo, discutindo as relações entre pesquisa e indústria farmacêutica e profissional de assistência. ${ }^{10}$

A mudança no perfil do médico, com uma enorme penetração de mulheres nas escolas de medicina (elas perfazem ao menos metade dos estudantes no Brasil e nos países desenvolvidos) contribui para uma mudança prática das atividades profissionais, com a necessidade de horários mais flexíveis ou horários limitados, a fim de permitir uma conciliação entre vida familiar e profissional, sob pena de limitar insuportavelmente a mão de obra disponível. Na Inglaterra mais de $50 \%$ dos estudantes de medicina a partir de 1990 são do sexo feminino, mas apenas $2 \%$ das mulheres escolhem cirurgia como carreira, baseadas em argumentos quanto à qualidade de vida, o que determina aprioristicamente uma diminuição séria no contingente de cirurgiões futuros e tem obrigado à busca de soluções para o impasse. ${ }^{11}$

O controle crescente da qualidade de trabalho médico a partir de instituições governamentais e mídia também tem criado problemas em atrair mão de obra cirúrgica. Os maiores contingentes de processos de erro médico no país são contra ginecologistas e cirurgiões, e há uma tendência a desconsiderar os limites da atividade médica e da vida humana de forma geral, criando uma cultura de culpa e castigo frente a quaisquer fatos clínicos desfavoráveis, mesmo que inevitáveis ou incidentais frente a uma reflexão mais profunda. No Brasil, denunciar erros médicos suspeitos é extremamente fácil, gratuito e facilmente abraçado pela mídia, enquanto que desagravos a profissionais injustamente agredidos e amplamente expostos publicamente são excepcionais.

A necessidade de controle de qualidade no trabalho médico é inquestionável, e idéias quanto à re-certificação periódica de profissionais são dominantes, mas criam novos 
mecanismos de pressão sobre os profissionais. Nos EUA 5 a $10 \%$ dos médicos de todas as especialidades falham nos exames de re-certificação obrigatória. ${ }^{12}$ A atualização permanente, sem dúvida necessária, não é de aquisição fácil: há inúmeras fontes de literatura médica (mais de 75 revistas mensais de cirurgia só em língua inglesa!) a serem esgotadas. Os custos financeiros da formação profissional estão cada vez maiores, em especial em atividades de alta tecnologia (video-cirurgia é uma delas), não têm paralelo em apoio financeiro de empregadores e raramente são amortizadas por aumento significativo dos ganhos do profissional.

Problemas humanos como a diminuição cognitiva secundária ao processo de envelhecimento e doenças eventuais também precisam ser considerados. $\mathrm{O}$ que fazer com o profissional reprovado nas re-certificações? Etapas remuneradas de reciclagem? Suspensão remunerada de atividades até nova chance de re-certificação? Seguros de garantia?

Evidentemente todos os problemas da natureza humana atingem médicos, mas entre eles as taxas de doença física e mental grave são maiores, presumivelmente devido ao estresse profissional. Nos Estados Unidos cerca de 10\% dos médicos são etilistas e 5\% droga-aditos. $16 \%$ sofrem de alguma forma de distimia. ${ }^{12} \mathrm{Na}$ Alemanha $50 \%$ dos cirurgiões acima dos 50 anos têm problemas graves de saúde e $7 \%$ são etilistas crônicos. ${ }^{2}$

Todos estes problemas têm aumentado a frequência da síndrome da exaustão emocional ("burn-out”) entre médicos e entre cirurgiões especificamente. A síndrome de exaustão emocional está diretamente ligada ao desejo de abandonar a atividade, ódio ou desprezo ao trabalho e baixa produtividade, que evidentemente podem representar perigo para os pacientes. ${ }^{13}$ Uma pesquisa recente entre cirurgiões de transplante nos EUA (especialistas com alto índice de status financeiro e profissional) demonstrou $38 \%$ de síndrome de "burnout", $27 \%$ de depressão e $16 \%$ de déficit de auto-estima. ${ }^{14} \mathrm{No}$ Brasil, pesquisa semelhante entre oncologistas mostrou $16 \%$ de "burn-out", em especial despersonalização e exaustão emocional, relacionadas pelos profissionais com excesso de trabalho, pequena autonomia e auto-gerenciamento em instituições privadas e baixa qualidade de vida.${ }^{15} \mathrm{~A}$ taxa de suicídios entre médicos e estudantes de medicina entre 20 e 39 anos em São Paulo é quase 4 vezes maior que a da população em geral (superada apenas pelos policiais), e é a maior causa de óbitos na profissão, nesta faixa etária (11\%). ${ }^{16} \mathrm{Na}$ Bahia, 26\% dos médicos sofrem de distúrbios psiquiátricos, piores para mulheres, profissionais solteiros, < 45 anos e com antecedentes psiquiátricos, sendo 3 vezes mais freqüentes naqueles em posições de grande demanda emocional e pequeno controle sobre o trabalho. ${ }^{17}$

Um dos grandes problemas enfrentados pelos médicos é a força dos estereótipos profissionais, empregados num meio extremamente competitivo. Médicos são "internamente" perfeccionistas, conscienciosos e controladores. Necessitam de aprovação social, são estóicos e se colocam freqüentemente em dúvida. "Externamente" precisam ser seguros, corajosos e socialmente inquestionáveis. Há que ser o melhor embora haja apenas um melhor de todos a cada momento, por definição. A expectativa é altíssima, o próprio profissional, da sociedade e dos pares, e cada um dos médicos (pior em cirurgiões!) está dolorosamente ciente de suas próprias limitações.

Tem sido documentado que a disponibilidade de bons modelos de formação atrai jovens para especialidades cirúrgicas. Um bom internato em cirurgia (OR 2,8) e o interesse em pesquisa acadêmica (OR 2,1) aumentam o número de alunos interessados em cirurgia, enquanto que alunos interessados em praticar em regiões rurais $(\mathrm{OR} 0,6)$ e mulheres $(\mathrm{OR} 0,4)$ não têm atração por cirurgia. Entre os estudantes americanos 7\% optam por cirurgia geral, contra $10 \%$ em especialidades cirúrgicas, melhor remuneradas. $8 \%$ das mulheres escolhem cirurgia, contra $23 \%$ dos estudantes do sexo masculino. ${ }^{18}$

Ensinar cirurgia depende de mecanismos formais (sala de aula, discussão de enfermaria, discussões de casos, conferências, seminários) e informais (conversas no ambiente hospitalar, contato para assimilação de padrões e modelos de comportamento, confidências no bar). Muitas das regras de atuação profissional são consensuais e não escritas. A educação informal é fundamental nesta assimilação, principalmente no que concerne ética, humanismo e apoio à adaptação e homeostase psico-social do profissional. O papel formador do mentor profissional é essencial, mas em geral este não o percebe objetivamente: o exemplo profissional é puntual, circunstancial e não reflexivo. Ao menos parte deste currículo "escondido" deve ser formalizado, com a inclusão de temas de filosofia, ética e comportamento, mas o papel da formação prática à beira do leito no convívio com a medicina "real" jamais poderá ser substituído no amadurecimento de fatos, idéias e conflitos. Conhecimento tático e formal se complementam, e uma plataforma moral é fundamental como base para o trabalho do médico. A relação já complexa entre médico e comunidade tem sido mais complicada pela consideração de trabalho médico enquanto prestação de serviço, transformando o paciente em "consumidor" e suscitando gerenciamento por produtividade. Estas novas formas de idealização do trabalho médico têm diminuído a gerência do profissional sobre o seu próprio trabalho e remuneração e criado circunstâncias de "resolver a fila" como prioridade absoluta e relativamente independente de qualidade em atendimento, assimiladas pelos aprendizes.

A importância dos modelos profissionais (pessoas capazes de fazer o que gostaríamos nas posições que pretendemos alcançar) na determinação de valores profissionais e comportamentos dos profissionais jovens sem dúvida persiste, mas é sem dúvida diferente. O julgamento dos graduandos a respeito dos "mestres" tem sido mais crítico? Pesquisa recente demonstrou que valores como empatia, respeito aos pacientes e integridade são importantes para os alunos, ao lado de competência profissional, habilidade interesse para ensinar. Status acadêmico e reconhecimento como pesquisador não são tão valorizados pelos estudantes. Lamentavelmente, a mesma pesquisa refere que os comportamentos efetivamente absorvidos pelos estudantes nem sempre coincidem com estes ideais: o comportamento dos mais novos reproduz diretamente aquele dos detentores de maior poder e status, num nítido confronto entre ideal e fato prático. ${ }^{19}$

O famoso relatório Flexner, de 1910, responsável por modificar os paradigmas da educação médica americana, foi 
direcionado para o público geral. Mais conhecido pelas críticas ao modelo de formação médica até então vigente, propôs um redirecionamento da educação médica conforme um modelo cientificista positivista, que deveria substituir o aprendizado pelo exemplo e autoridade do mentor por um modelo baseado no convívio clínico determinando o aprendizado e as linhas de pesquisa clínica a partir de questões suscitadas pela prática, unificando as figuras do assistente, do professor, do modelo profissional e do pesquisador ("think much, publish little"). Este modelo, levado ao máximo desempenho na Universidade de Harvard junto com as idéias Halstedianas de ensino de cirurgia (estrutura de residência médica), foi rapidamente superado pela sofisticação progressiva dos instrumentos e temas de pesquisa, pelos julgamentos de mérito excessivamente pragmáticos, dependentes exclusivamente da quantidade de publicações, e pelo gerenciamento de produtividade, que determinou uma quantidade crescente de trabalho prático mensurado (e pago!) de forma instrumental. Estes mecanismos de controle divorciaram prática, pesquisa e ensino, e, do ponto de vista filosófico, fizeram esquecer que conhecimento em medicina é apenas instrumento da prática com o paciente, e fundamentação moral é fundamental (e neste parti- cular o papel do convívio com o "mestre" e o profissional no dia a dia é insubstituível).

As motivações para o exercício profissional dos estudantes de medicina interessados em cirurgia em fim de curso na Europa dependem do exercício de atividade clínica e responsabilidade com o cuidado de pacientes $(90 \%)$ e interesse por estudantes e contato profissional com cirurgiões experientes, criando modelos profissionais ( $80 \%$ ), preferencialmente sob um nível baixo de estresse. Mesmo assim cirurgiões participam cada vez menos na educação de estudantes de graduação de forma direta, pressionados pela carga de trabalho exaustiva e necessidades gerenciais de produtividade. De fato, o trabalho do cirurgião tem sido cada vez mais apresentado por não-cirurgiões, com os vieses correspondentes sobre os estudantes. ${ }^{2}$ reconhecidas.

Frente a todos estes problemas, poucas soluções já

Sem dúvida, temos uma necessidade premente e imperativa de refletir - muito - sobre estas questões. Sem sombra de dúvida as revistas científicas de cirurgia devem reconhecê-las como prioridades, que determinam a qualidade do exercício profissional, e abrir espaço para a discussão destes problemas.

\begin{abstract}
The autor discusses the crisis concerning education and professional life for doctors and surgeons making a review of contemporary data concerning professional epidemiology. We reflect on the modern ethical and social references to the medical profession. There is a decline in medical schools preparing doctors and surgeons, and a progressive "feminization" of the profession. Young professionals want quality of life and professional autonomy as their main professional objectives. Burn-out syndromes are common between doctors, and loss of professional autonomy may be the main cause of the disease. The crisis that attains the medical profession in our days has been ethical, social and financial roots. It is essential to discuss new paradigms in medical education and professional routine, concerning the modern society.
\end{abstract}

Key words: Education, medical; Surgery/education; Schools, medical; Students, Medical.

\section{REFERÊNCIAS}

1. Blanchard S. La France manque dês pédiatres. Le Monde. 2007 Avril 04.

2. Neuhaus P. Why should young doctors choose to become surgeons? Ann Surg. 2007;246(6):911-5.

3. Harder F. "I would like to be a surgeon, but." Ann Surg. 2002;236(6):699-702.

4. Debas HT. Surgery: a noble profession in a changing world. Ann Surg. 2002;236(3):263-9.

5. Ziegler MM. Pediatric surgical training: an historic perspective, a formula for change. J Pediatr Surg. 2004;39(8):1159-72.

6. Machado MH (coord). Perfil dos Médicos no Brasil: relatório final. Fiocruz/CFM, 1997.

7. Relação candidato-vaga, prova de residência médica 2007, UFRJ/ RJ. Acessada de http://www.residencia.ufrj.br em 03 janeiro 2008.

8. Relação candidato-vaga, prova de residência médica 2007, UFPR/ PR. Acessada de http://www.nc.ufpr.br/concursos_institucionais, em 03 janeiro 2008.

9. (autor não declarado) Oferta das vagas de residência reflete desorganização do mercado de trabalho. UNIFESP, acessada de http://www.unifesp.br/comunicacao/jpta/ed117/reside3.htm em 3 janeiro 2008.

10. Loefler I. Why the Hippocratic ideals are dead. BMJ. 2002;324(7351):1463.

11. Smith NP, Dykes EH, Youngson GS, Losty PD. Is the grass greener? A survey of female pediatric surgeons in the United Kingdom. J Pediatr Surg. 2006;41(11):1879-81.

12. Leape LL. When good doctors go bad: a systems problem. Ann Surg. 2006;244(5):649-52.

13. Persaud R. The drama of being a doctor. Postgrad Med J. 2005; 81(955):276-7.

14. Bertges Yost W, Eshelman A, Raoufi M, Abouljoud MS. Anational study of burnout among American transplant surgeons. Transplant Proc. 2005;37(2):1399-401.

15. Tucunduva LT, Garcia AP, Prudente FVB, Centofanti G, Souza CM, Monteiro TA, Vince FA, Samano ES, Gonçalves MS, Del Giglio A. [Incidence of burnout syndrome among Brazilian cancer physicians]. Rev Assoc Med Bras. 2006;52(2):108-12.

16. Yuri D. Médico é mais suscetível a cometer suicídio. Folha de São Paulo. 2001 Nov 18; C7. 
17. Nascimento-Sobrinho CL, Carvalho FM, Bonfim TAS, et al. Condições de trabalho e saúde mental dos médicos de Salvador, Bahia, Brasil. Cad Saúde Pública. 2006;22(1):131-40.

18. Andriole DA, Klingensmith ME, Jeffe DB. Who are our future surgeons? Characteristics of medical school graduates planning surgical careers: analysis of the 1997 to 2004 Association of American Medical Colleges' Graduation Questionnaire National Database. J Am Coll Surg. 2006;203(2):177-85. Epub 2006 Jun 23.

19. Paice E, Heard S, Moss F. How important are role models in making good doctors? MJ. 2002;325:707-10.
Como citar este artigo:

Jesus LE. Ensinar cirurgia: como e para quem? Rev Col Bras Cir. [periódico na Internet] 2008; 35(1). Disponível em URL: http:// www.scielo.br/rcbc

Endereço para correspondência:

Lisieux Eyer de Jesus

R Presidente Domiciano, 52/801

Boa Viagem

24210-270 - Niterói - RJ

E-mail: lisieux@uol.com.br 